\title{
Glass Superstrate Nanoantennas for Infrared Energy Harvesting Applications
}

\author{
Isa Kocakarin and Korkut Yegin \\ Department of Electrical \& Electronics Engineering, Yeditepe University, 34755 Istanbul, Turkey \\ Correspondence should be addressed to Korkut Yegin; kyegin@yeditepe.edu.tr
}

Received 6 September 2012; Accepted 27 November 2012

Academic Editor: Xianying Wang

Copyright ( 2013 I. Kocakarin and K. Yegin. This is an open access article distributed under the Creative Commons Attribution License, which permits unrestricted use, distribution, and reproduction in any medium, provided the original work is properly cited.

Several nanoantennas for infrared energy harvesting applications at $30 \mathrm{THz}$ are studied. Contrary to usual antenna designs, we implemented glass superstrate as opposed to glass substrate for better antenna performance. We defined a figure of merit (FOM) which includes antenna fractional bandwidth, peak gain, and half-power beamwidth of the antenna under consideration. Three different antenna structures with glass superstrate and one of them with glass substrate are studied in detail. According to our FOM definition, the Archimedean balanced spiral antenna exhibited superior performance among other structures with less sensitivity to the incoming polarization of the electromagnetic wave.

\section{Introduction}

With the increasing applications of nanoantennas that can focus electromagnetic energy into small localized area [19], energy harvesting gained more attention and considerable research has been devoted to it [10-14]. Energy harvesting at visible spectrum of electromagnetic waves has been mostly achieved using monocrystalline silicon which is an expensive process. On the other hand, thermal radiation which is between 7 and $16 \mu \mathrm{m}$ falls into infrared (IR) region of the spectrum and provides opportunity for most of the available ambient energy at room temperature. Despite the fact that the amount of energy at IR is smaller than that of the visible spectrum, energy conversion at IR can be more promising due to relatively less expensive and complicated processes involved in the conversion devices. The diode structures utilized in the photon-electron conversion process are usually either metal-oxide-metal or metal-insulator-metal type diodes and can be incorporated within the feed gap of the antenna [15-18].

Antennas for IR applications follow quite similar guidelines with those at RF region [19-30]. The radiation efficiency, directivity, and bandwidth play an important role for the overall antenna performance. One important aspect of these antennas is that they must be polarization insensitive simply because incoming electromagnetic signal has no preferred polarization; it is rather arbitrary. Similar to those antennas used in indoor communications, the antennas can be made circularly polarized and they can pick up almost any polarized signal except those with crosspolarization. However, circular polarization is difficult to achieve with external components, and rather the antenna must be inherently built with such polarization. Examples of such antenna structures are abundant in RF applications. Nevertheless, simple structures that are easy to manufacture are primary choices for designers at nanoscale lengths. In that respect, we also considered crossed dipole, bowtie, Archimedean spiral, and balanced crossed dipole geometries for IR detection. Our analysis is based on radiation properties of these antenna structures, but their reception properties are identical to their transmission ones according to Reciprocity theory.

In our antenna study, we propose two different structures: one that utilizes glass as a superstrate and the other glass as a substrate. For both geometries, different antenna structures are simulated and a figure of merit which depends on antenna peak gain, half-power beam width, and fractional bandwidth is defined and compared for all structures. 

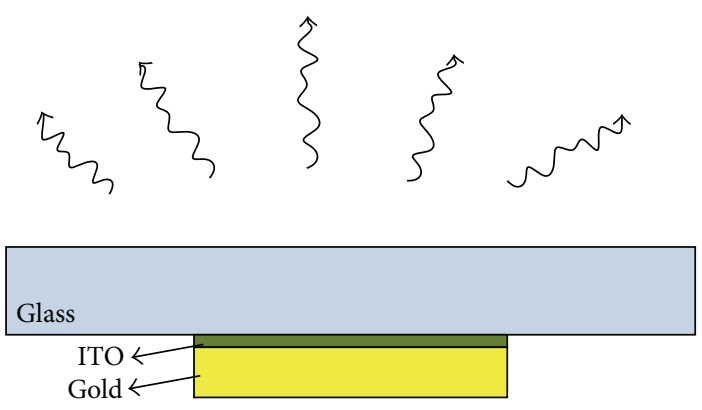

FIGURE 1: Glass superstrate antenna.

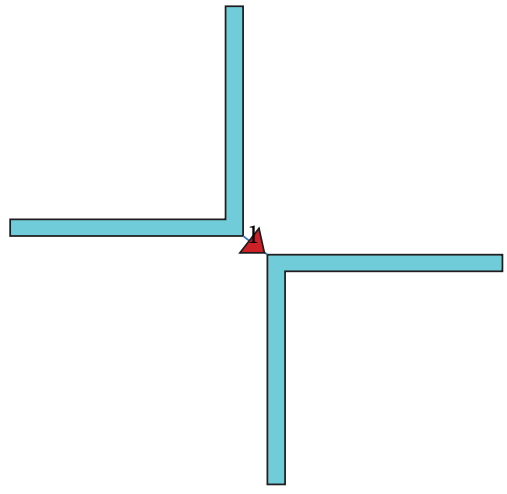

(a)

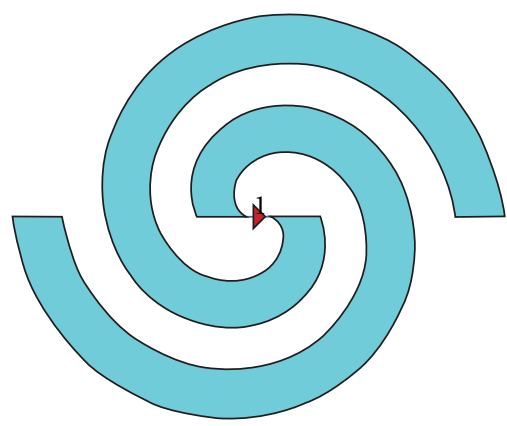

(c)

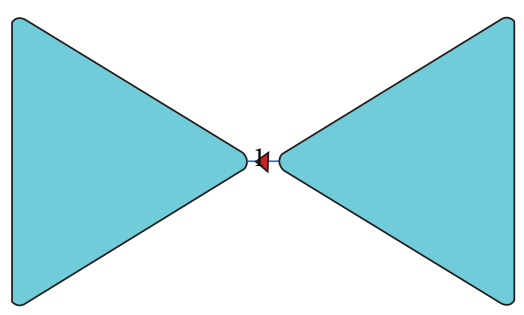

(b)

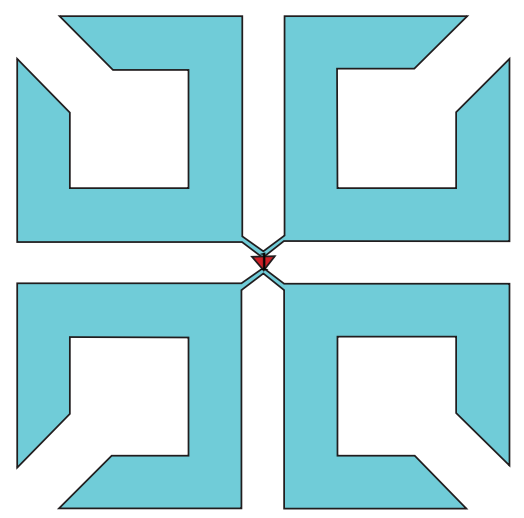

(d)

Figure 2: Nanoantenna structures considered for infrared applications, (a) crossed dipole, (b) bowtie, (c) Archimedean spiral, and (d) modified crossed dipole.

\section{Antenna Designs}

We consider glass superstrate (pyrex) with indium tin oxide (ITO) and gold imprinted on lower side as shown in Figure 1.

Drude model of gold is used in the simulations. CST Microwave studio, a 3D electromagnetic field solver based on finite integration technique, is used for simulations. Drude model of gold has been extensively studied before, and the relative dielectric constant of gold is approximated as

$$
\varepsilon_{r}(\omega)=1-\frac{\omega_{p}^{2}}{\omega^{2}+i \gamma \omega},
$$

where $\omega_{p}$ and $\gamma$ are the plasma frequency and collusion frequency, respectively. The values of $\omega_{p}$ and $\gamma$ are $1.216 \times 10^{16} \mathrm{rad} / \mathrm{s}$ and $0.2 \times 10^{14} \mathrm{rad} / \mathrm{s}$. We considered crossed dipole (CD) antenna, bowtie antenna, spiral antenna, and modified crossed dipole (MCD) antenna for infrared applications. The structures are shown in Figure 2.

To assess the performance of each antenna structure a figure of merit (FOM) is defined as

$$
\mathrm{FOM}=\frac{\mathrm{HPBW}}{\pi} \times \text { Peak Gain }(@ 10 \mu \mathrm{m}) \times \mathrm{FBW}
$$




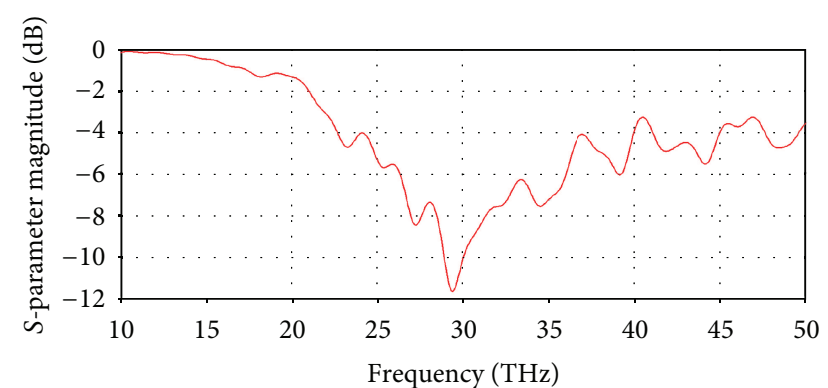

FIgURE 3: Magnitude of input reflection coefficient (in dB).

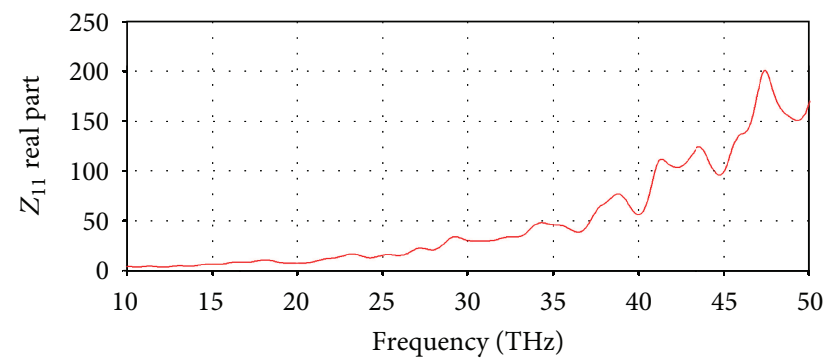

(a)

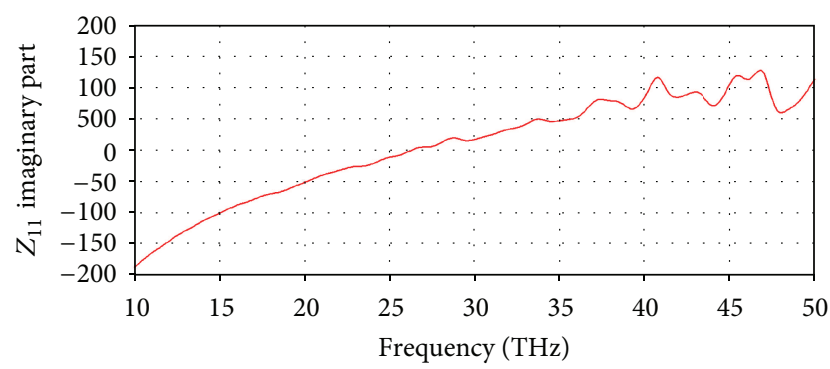

(b)

FIGURE 4: Input impedance of crossed dipole: (a) resistance and (b) reactance.

where HPBW is the half-power beam width and FBW is the fractional bandwidth, defined as

$$
\mathrm{FBW}=\frac{\left(f_{1}-f_{2}\right)}{f_{c}},
$$

where $f_{c}$ is the center frequency for the frequency band. The impedance frequency bandwidth is defined as the band of frequencies where the magnitude of the input reflection coefficient drops below $-8 \mathrm{~dB}$. This FOM is unitless and is used for all optimized antenna structures for comparison.

\section{Results and Discussion}

Crossed dipole with $50 \mathrm{~nm}$ ITO and $50 \mathrm{~nm}$ gold thickness on a $20 \times 20 \times 5 \mu \mathrm{m}$ glass substrate is considered first. On half arm length is taken as $950 \mathrm{~nm}$ and width of the arm is taken as $80 \mathrm{~nm}$. Normally, resonant antenna length at free space is expected to be around $5 \mu \mathrm{m}$ for $30 \mathrm{THz}$ radiation, but due to glass superstrate, the resonant dimension is reduced

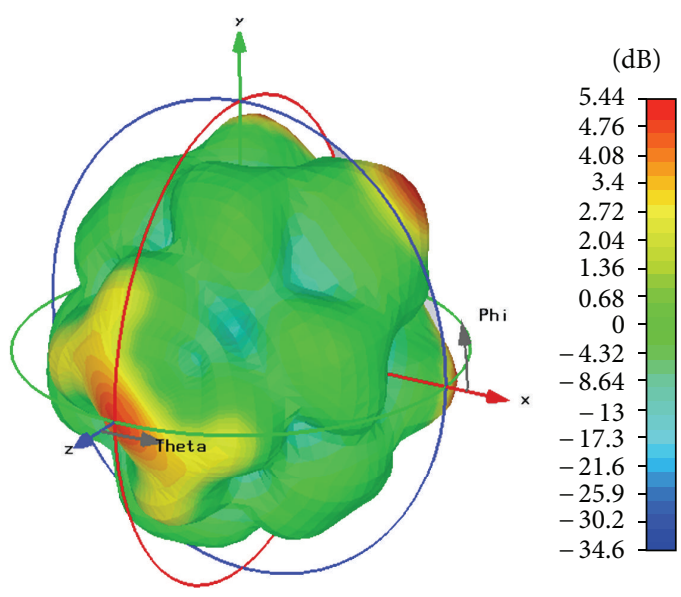

(a)

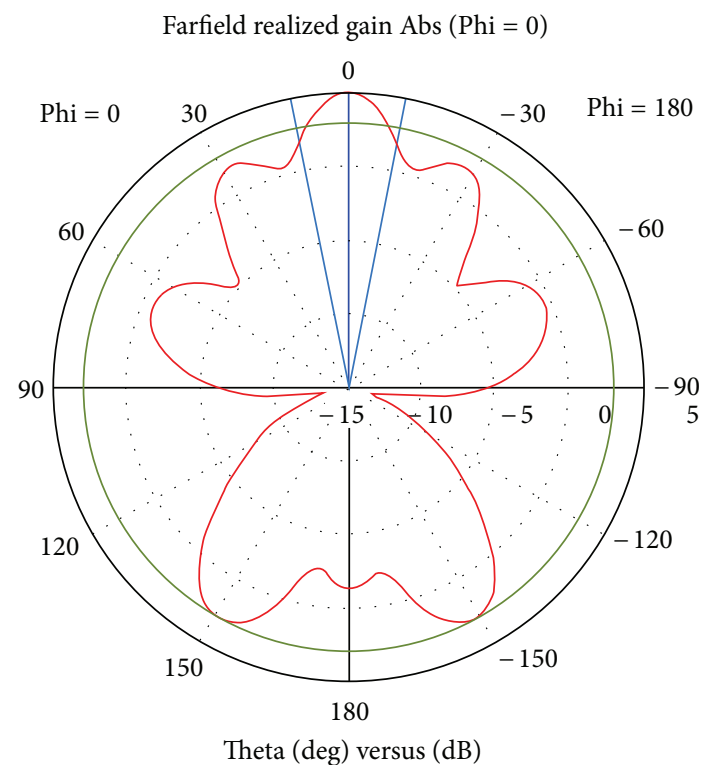

(b)

FIGURE 5: Radiation pattern of crossed dipole: (a) 3D pattern and (b) $2 \mathrm{D}$ elevation cuts at $\mathrm{phi}=0^{\circ}$.

to approximately $2 \mu \mathrm{m}$. The magnitude of input reflection coefficient is shown in Figure 3. Corresponding input impedance real and imaginary parts are shown in Figures 4(a) and $4(\mathrm{~b})$.

Realized gain, that is, mismatch loss subtracted from directivity, is shown in Figures 5(a) and 5(b). The peak gain for vertically polarized pattern is $4.9 \mathrm{dBi}$. The FOM comes about 0.0365 .

Next, we studied bowtie antenna element on $20 \times 20 \times$ $5 \mu \mathrm{m}$ glass superstrate. The ITO and gold thicknesses are $5 \mathrm{~nm}$ and $150 \mathrm{~nm}$, respectively. Bowtie has $74^{\circ}$ flare angle, and the length of one arm is $900 \mathrm{~nm}$, again smaller than its free-space counterpart by about $1 / 5$ th. The magnitude of input reflection coefficient with $50 \Omega$ reference is given in Figure 6. The input impedance is displayed in Figures 7(a) and 7(b). 


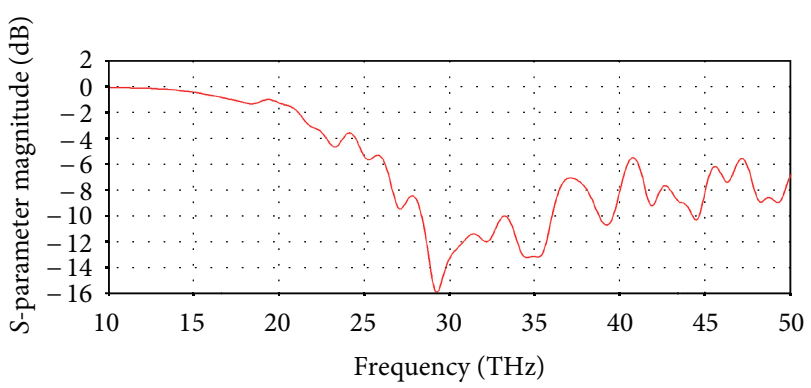

Figure 6: Input reflection coefficient of bowtie antenna.

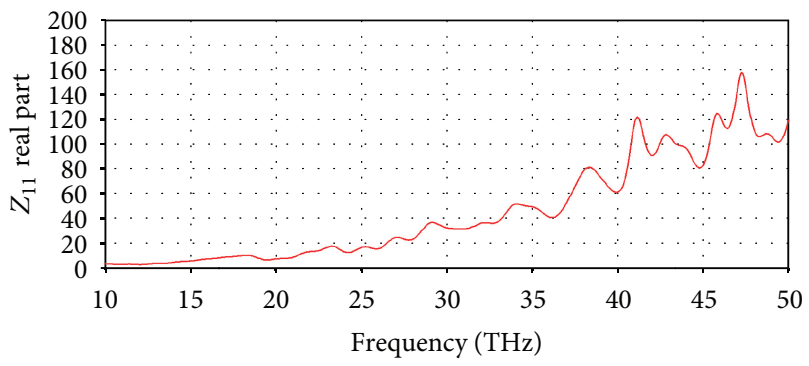

(a)

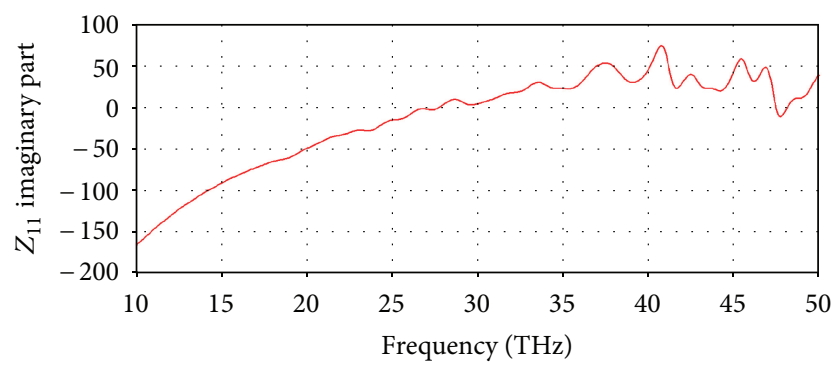

(b)

FIGURE 7: Input impedance of optimized bowtie antenna: (a) resistance and (b) reactance.

The radiation patterns of bowtie antenna are shown in Figures $8(\mathrm{a})$ and $8(\mathrm{~b})$. Peak gain is found to be $5.3 \mathrm{dBi}$ and HPBW is $21.9^{\circ}$. Calculated FOM for bowtie antenna is 0.129 .

Next, we considered balanced Archimedean spiral antenna. The glass superstrate is taken as $8 \times 8 \times 4 \mu \mathrm{m}$. The ITO and gold antenna thicknesses are $5 \mathrm{~nm}$ and $50 \mathrm{~nm}$, respectively. The width and arm length of the spiral arm are $200 \mathrm{~nm}$ and $500 \mathrm{~nm}$, respectively. Feed gap of $50 \mathrm{~nm}$ is taken in the simulations. The input reflection coefficient magnitude with reference to $50 \Omega$ is shown in Figure 9 .

The input impedance of spiral antenna is shown in Figures 10(a) and 10(b).

The radiation patterns of balanced Archimedean spiral antenna are shown in Figures 11(a) and 11(b). The HPBW is about $69^{\circ}$ and peak gain is $6.3 \mathrm{dBi}$. Calculated FOM is 0.41 . Balanced spiral antenna has larger bandwidth because its active surface has rotational symmetry at different operation frequencies. While the longest length is resonant at lower end of the frequency band, its active area shrinks as frequency is increased. Because it preserves its structural symmetry as

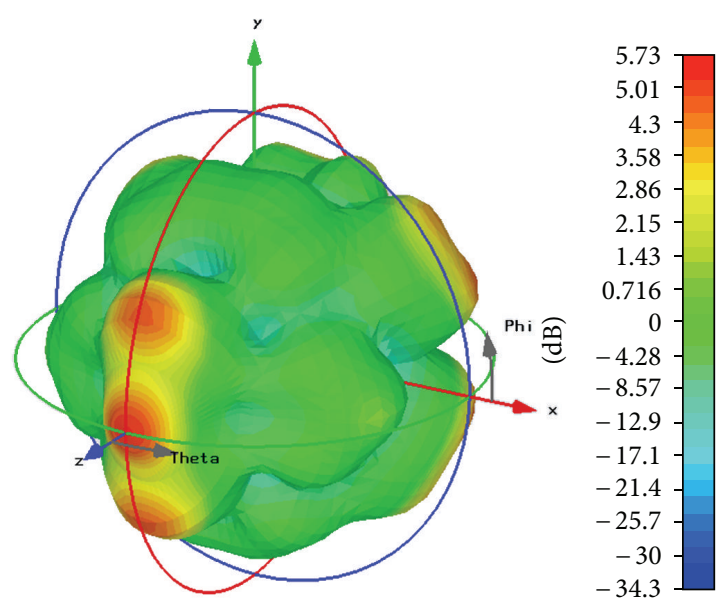

(a)

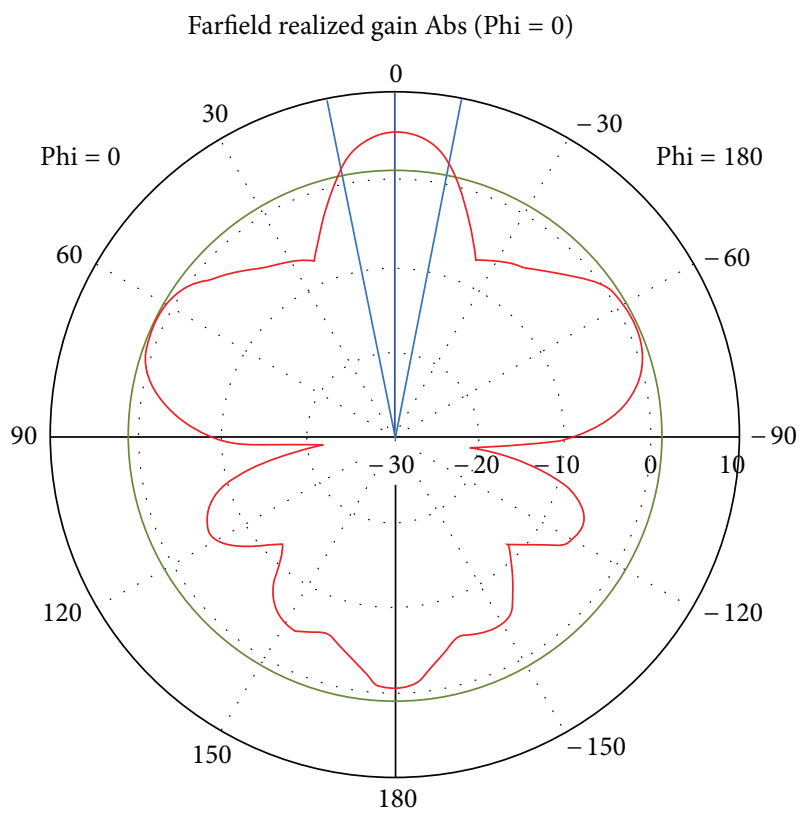

Theta (deg) versus (dB)

(b)

FIGURE 8: Radiation pattern of bowtie: (a) 3D and (b) 2D elevation cuts for phi $=0^{\circ}$.

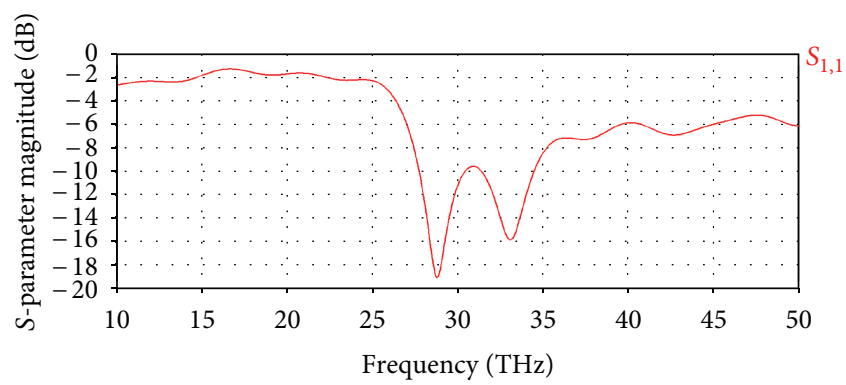

FIGURE 9: Magnitude of input reflection coefficient for balanced Archimedean spiral antenna. 


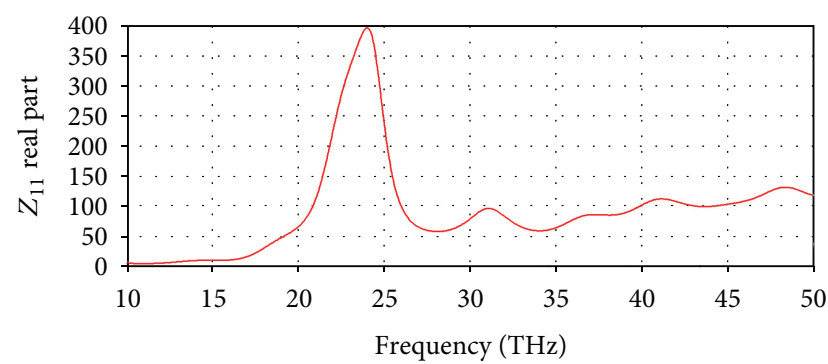

(a)

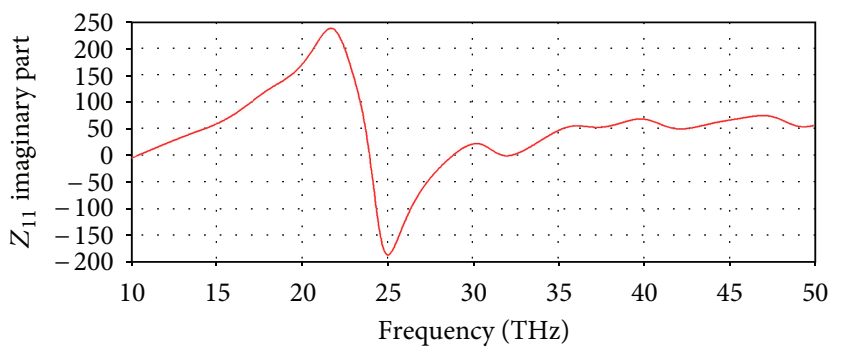

(b)

Figure 10: Input impedance of Archimedean spiral antenna: (a) resistance and (b) reactance.

TABLE 1: Performance comparison of antennas.

\begin{tabular}{lcccc}
\hline & Crossed dipole & Bowtie & Spiral & MCD \\
\hline$f_{c}(\mathrm{THz})$ & 29.86 & 31.53 & 31.3 & 28.82 \\
FBW & 0.094 & 0.309 & 0.248 & 0.111 \\
$G$ (linear) & 3.09 & 3.43 & 4.29 & 1.39 \\
HPBW (deg) & 22.6 & 21.9 & 69 & 56 \\
FOM & 0.036 & 0.131 & 0.408 & 0.046 \\
\hline
\end{tabular}

frequency changes, the antenna phase center at the input terminals experiences less variation, which, in turn, makes it more wideband. It is also less sensitive to polarization as rotational structure captures all antenna-plane polarizations compared to bowtie and dipole-like structures.

Last structure we studied is modified crossed dipole (MCD) antenna for dual polarization applications. Contrary to previous structures, the glass is taken as a substrate and its dimensions are taken as $10 \times 10 \times 2 \mu \mathrm{m}$. The ITO and gold thicknesses are $5 \mathrm{~nm}$ and $100 \mathrm{~nm}$, respectively. The dimension of each arm is $1.68 \mu \mathrm{m}$. The magnitude of input reflections coefficient is presented in Figure 12.

The impedance of MCD antenna is shown in Figure 13.

Radiation patterns of MCD antenna are shown in Figures 14(a) and 14(b). The HPBW is $56^{\circ}$ and the peak gain at $10 \mu \mathrm{m}$ is $1.6 \mathrm{dBi}$. The FOM is calculated as 0.051 .

\section{Conclusions}

Glass superstrate as opposed to glass substrate can offer substantial improvement for antenna characteristics, which are measured in terms of antenna match bandwidth, peak realized gain, and half-power beamwidth. We combined

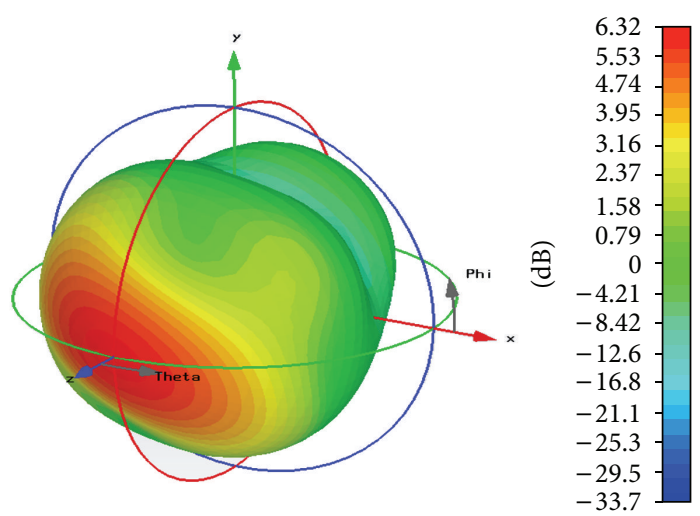

(a)

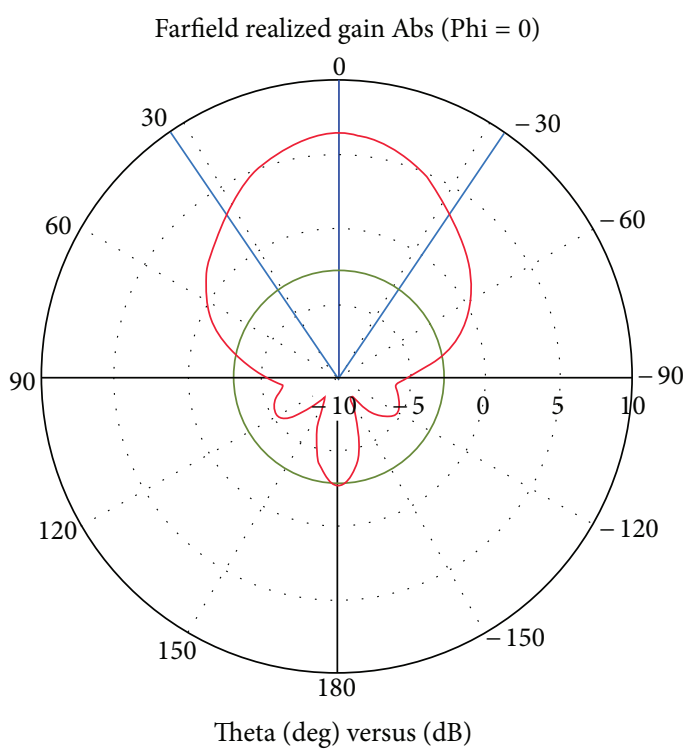

(b)

FIGURE 11: Radiation pattern of Archimedean spiral antenna: (a) 3D and (b) elevation cuts at phi $=0^{\circ}$.

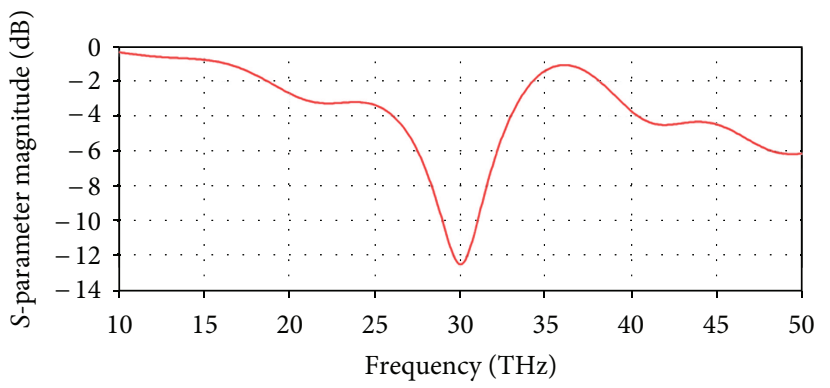

FIGURE 12: Magnitude of input reflection coefficient for modified crossed-dipole.

all these metrics into a single one and called it FOM. Comparison of FOMs for all structures is shown in Table 1. It is obvious that balanced Archimedean spiral antenna performs best among all other structures. In addition, this balanced spiral antenna is almost polarization insensitive for 


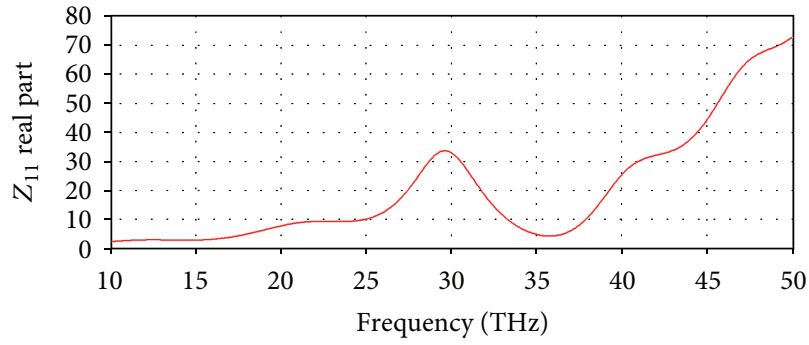

(a)

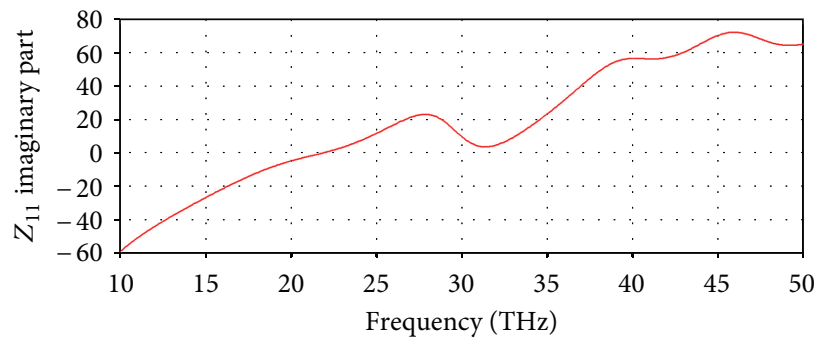

(b)

FIGURE 13: Input impedance of MCD antenna as a function of frequency: (a) resistance and (b) reactance.

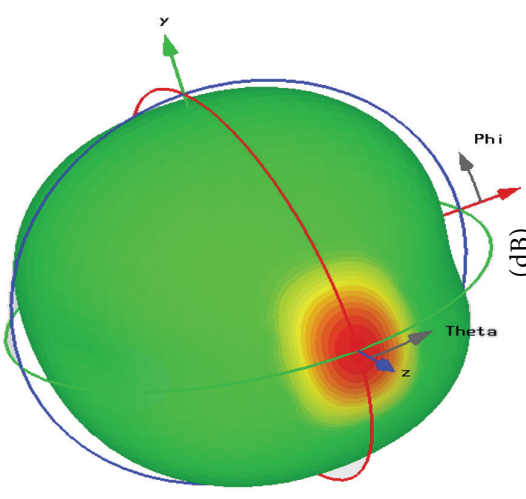

(a)

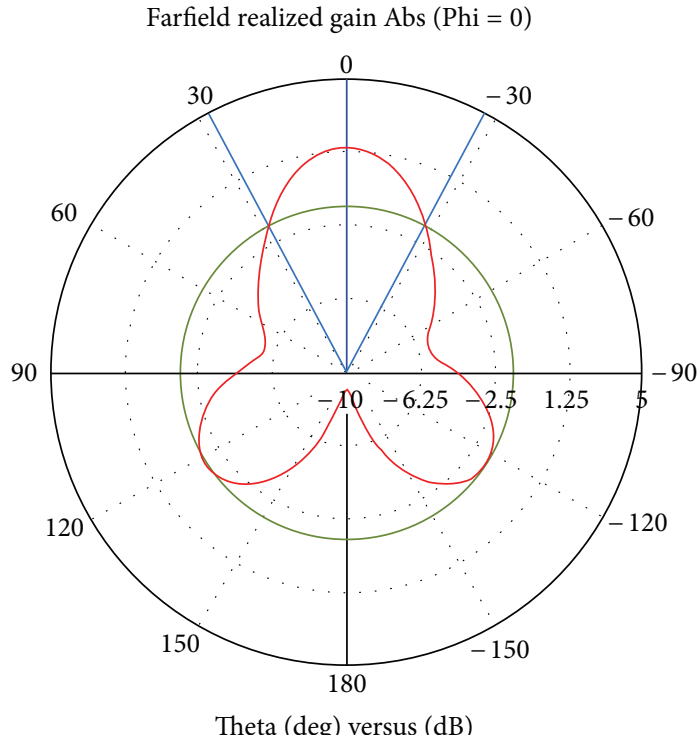

(b)

FIgURE 14: Radiation patterns of MCD antenna: (a) 3D pattern and (b) $2 \mathrm{D}$ elevation cut at phi $=0^{\circ}$.

in-plane polarized signals; that is, incoming polarization is arbitrary (no preferred polarization).

\section{Acknowledgments}

The authors express their thanks to Mehmet Ali Yesil for his assistance on simulations and to anonymous reviewers for their helpful suggestions. This work is partly funded by the Yeditepe University Research Fund.

\section{References}

[1] J. Alda, J. M. Rico-García, J. M. López-Alonso, and G. Boreman, "Optical antennas for nano-photonic applications," Nanotechnology, vol. 16, no. 5, pp. S230-S234, 2005.

[2] P. Muehlschlegel, H. J. Eisler, O. J. F. Martin, B. Hecht, and D. W. Pohl, "Resonant optical antennas," Science, vol. 308, no. 5728, pp. 1607-1609, 2005.

[3] P. Bharadwaj, B. Deutsch, and L. Novotny, "Optical antennas," Advances in Optics and Photonics, vol. 1, no. 3, pp. 438-483, 2009.
[4] L. Novotny and N. van Hulst, "Antennas for light," Nature Photonics, vol. 5, no. 2, pp. 83-90, 2011.

[5] V. Giannini, A. I. Fernandez-Dominguez, S. C. Heck, and S. A. Maier, "Plasmonic nanoantennas: fundamentals and their use in controlling the radiative properties of nanoemitters," Chemical Reviews, vol. 111, no. 6, pp. 3888-3912, 2011.

[6] M. Midrio, S. Boscolo, A. Locatelli, D. Modotto, C. de Angelis, and A. D. Capobianco, "Flared monopole antennas for $10 \mu \mathrm{m}$ energy harvesting," in Proceedings of the European Microwave Conference (EuMC '10), pp. 1496-1499, September 2010.

[7] M. Midrio, M. Romagnoli, S. Boscolo et al., "Flared monopole antennas for $10 \mu \mathrm{m}$ radiation," IEEE Journal of Quantum Electronics, vol. 47, no. 1, pp. 84-91, 2011.

[8] L. Wang, S. M. Uppuluri, E. X. Jin, and X. Xu, "Nanolithography using high transmission nanoscale bowtie apertures," Nano Letters, vol. 6, no. 3, pp. 361-364, 2006.

[9] A. Sundaramurthy, P. J. Schuck, N. R. Conley, D. P. Fromm, G. S. Kino, and W. E. Moerner, "Toward nanometer-scale optical photolithography: utilizing the near-field of bowtie optical nanoantennas," Nano Letters, vol. 6, no. 3, pp. 355-360, 2006.

[10] M. Heiblum, S. Wang, J. R. Whinnery, and T. K. Gustafson, "Characteristics of integrated MOM junction at dc and at 
optical frequencies,' IEEE Journal of Quantum Electronics, vol. 14, no. 3, pp. 159-169, 1978.

[11] A. Sanchez, C. F. Davis Jr., K. C. Liu, and A. Javan, "The MOM tunneling diode: theoretical estimate of its performance at microwave and infrared frequencies," Journal of Applied Physics, vol. 49 , no. 10 , pp. 5270-5277, 1978.

[12] I. Wilke, W. Herrmann, and F. K. Kneubühl, "Integrated nanostrip dipole antennas for coherent $30 \mathrm{THz}$ infrared radiation," Applied Physics B, vol. 58, no. 2, pp. 87-95, 1994.

[13] S. K. Masalmeh, H. K. E. Stadermann, and J. Korving, "Mixing and rectification properties of MIM diodes," Physica B, vol. 218, no. 1-4, pp. 56-59, 1996.

[14] F. J. Gonzales, B. Ilic, J. Alda, and G. D. Boreman, "Antennacoupled infrared detectors for imaging applications," IEEE Journal of Selected Topics in Quantum Electronics, vol. 11, no. 1, pp. 117-120, 2005.

[15] P. C. D. Hobbs, R. B. Laibowitz, and F. R. Libsch, "Ni-NiO-Ni tunnel junctions for terahertz and infrared detection," Applied Optics, vol. 44, no. 32, pp. 6813-6822, 2005.

[16] P. C. D. Hobbs, R. B. Laibowitz, F. R. Libsch, N. C. LaBianca, and P. P. Chiniwalla, "Efficient waveguide-integrated tunnel junction detectors at $1.6 \mu \mathrm{m}$," Optics Express, vol. 15, no. 25, pp. 16376-16389, 2007.

[17] C. Fumeaux, W. Herrmann, F. K. Kneubühl, and H. Rothizen, "Nanometer thin-film Ni-NiO-Ni diodes for detection and mixing of $30 \mathrm{THz}$ radiation," Infrared Physics \& Technology, vol. 39, no. 3, pp. 123-183, 1998.

[18] S. Krishnan, H. la Rosa, E. Stefanakos, S. Bhansali, and K. Buckle, "Design and development of batch fabricatable metalinsulator-metal diode and microstrip slot antenna as rectenna elements," Sensors and Actuators A, vol. 142, no. 1, pp. 40-47, 2008.

[19] F. Z. Gonzales and G. D. Boreman, "Comparison of dipole, bowtie, spiral and log-periodic IR antennas," Infrared Physics \& Technology, vol. 46, no. 5, pp. 418-428, 2005.

[20] J. A. Bean, B. Tiwari, G. Szakmány, G. H. Bernstein, P. Fay, and W. Porod, "Antenna length and polarization response of antenna-coupled MOM diode infrared detectors," Infrared Physics and Technology, vol. 53, no. 3, pp. 182-185, 2010.

[21] C. Middlebrook, P. Krenz, B. Lail, and G. Boreman, "Infrared phased array antenna," Microwave and Optical Technology Letters, vol. 50, no. 4, pp. 719-723, 2008.

[22] C. Middlebrook, M. Roggemann, G. Boreman et al., "Measurement of the mutual coherence function of an incoherent infrared field with a gold nano-wire dipole antenna array," International Journal of Infrared and Millimeter Waves, vol. 29, no. 2, pp. 179-187, 2008.

[23] T. A. Mandviwala, B. A. Lail, and G. D. Boreman, "Infraredfrequency coplanar striplines: design, fabrication, and measurements," Microwave and Optical Technology Letters, vol. 47, no. 1, pp. 17-20, 2005.

[24] J. Wen, S. Romanov, and U. Peschel, "Excitation of plasmonic gap waveguides by nanoantennas," Optics Express, vol. 17, no. 8, pp. 5925-5932, 2009.

[25] A. Kinkhabwala, Z. Yu, S. Fan, Y. Avlasevich, K. Müllen, and W. E. Moerner, "Large single-molecule fluorescence enhancements produced by a bowtie nanoantenna," Nature Photonics, vol. 3, no. 11, pp. 654-657, 2009.

[26] L. Novotny, "Effective wavelength scaling for optical antennas," Physical Review Letters, vol. 98, no. 26, Article ID 266802, 4 pages, 2007.
[27] R. D. Grober, R. J. Schoelkopf, and D. E. Prober, "Optical antenna: towards a unity efficiency near-field optical probe," Applied Physics Letters, vol. 70, no. 11, pp. 1354-1356, 1997.

[28] P. J. Burke, S. Li, and Z. Yu, "Quantitative theory of nanowire and nanotube antenna performance," IEEE Transactions on Nanotechnology, vol. 5, no. 4, pp. 314-334, 2006.

[29] H. Fischer and O. J. F. Martin, "Engineering the optical response of plasmonic nanoantennas," Optics Express, vol. 16, no. 12, pp. 9144-9154, 2008.

[30] M. L. Brongersma, "Plasmonics: engineering optical nanoantennas," Nature Photonics, vol. 2, no. 5, pp. 270-272, 2008. 

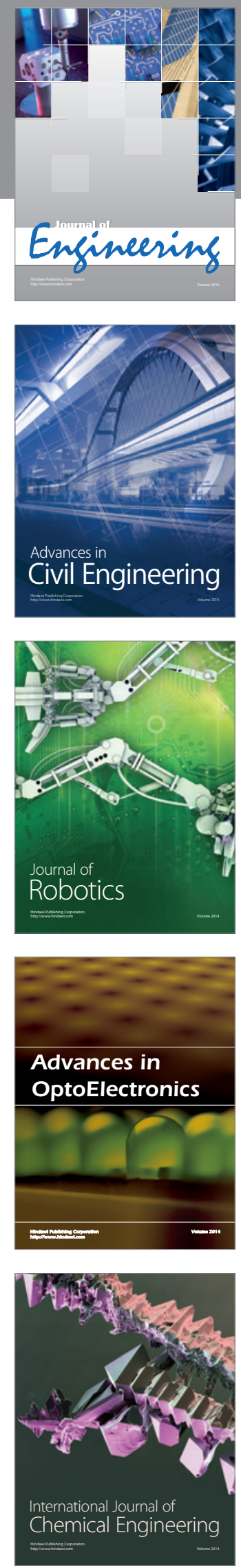

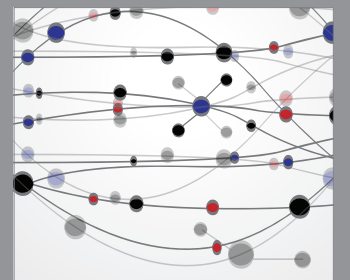

The Scientific World Journal
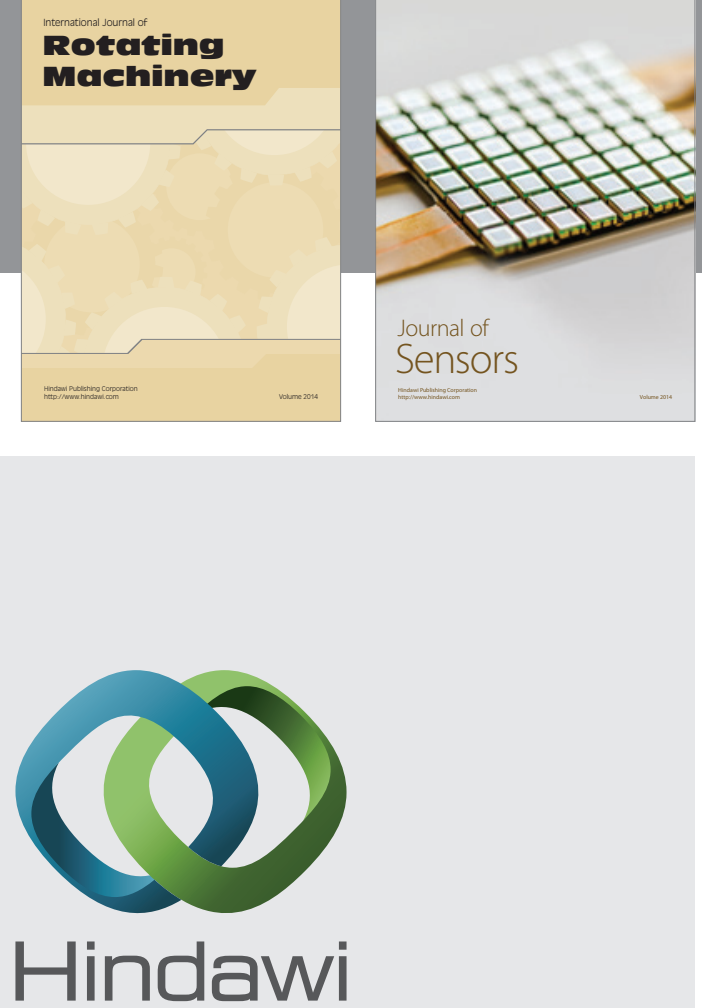

Submit your manuscripts at http://www.hindawi.com
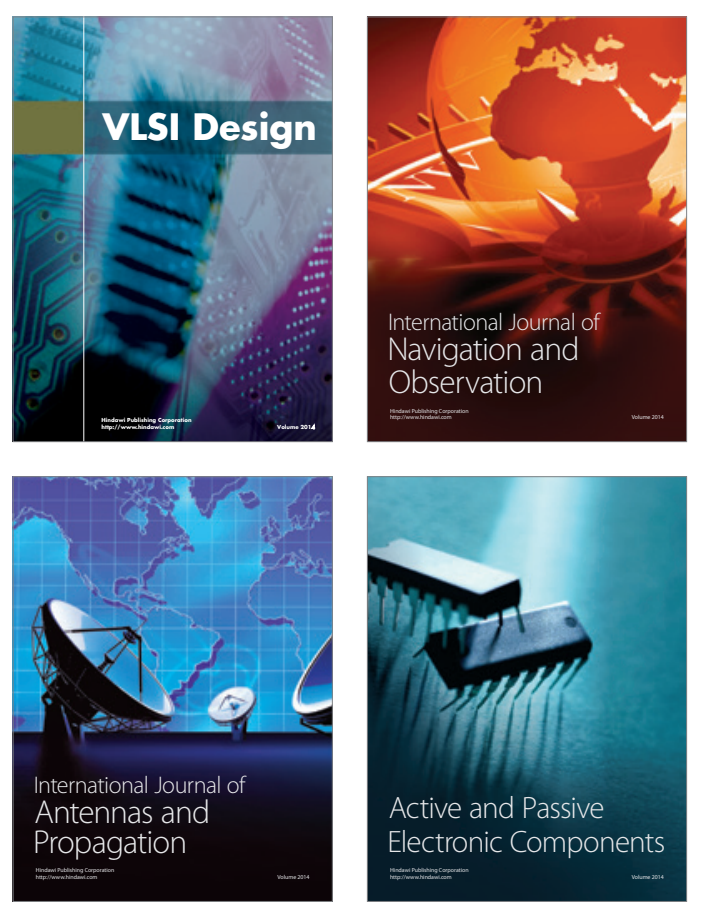
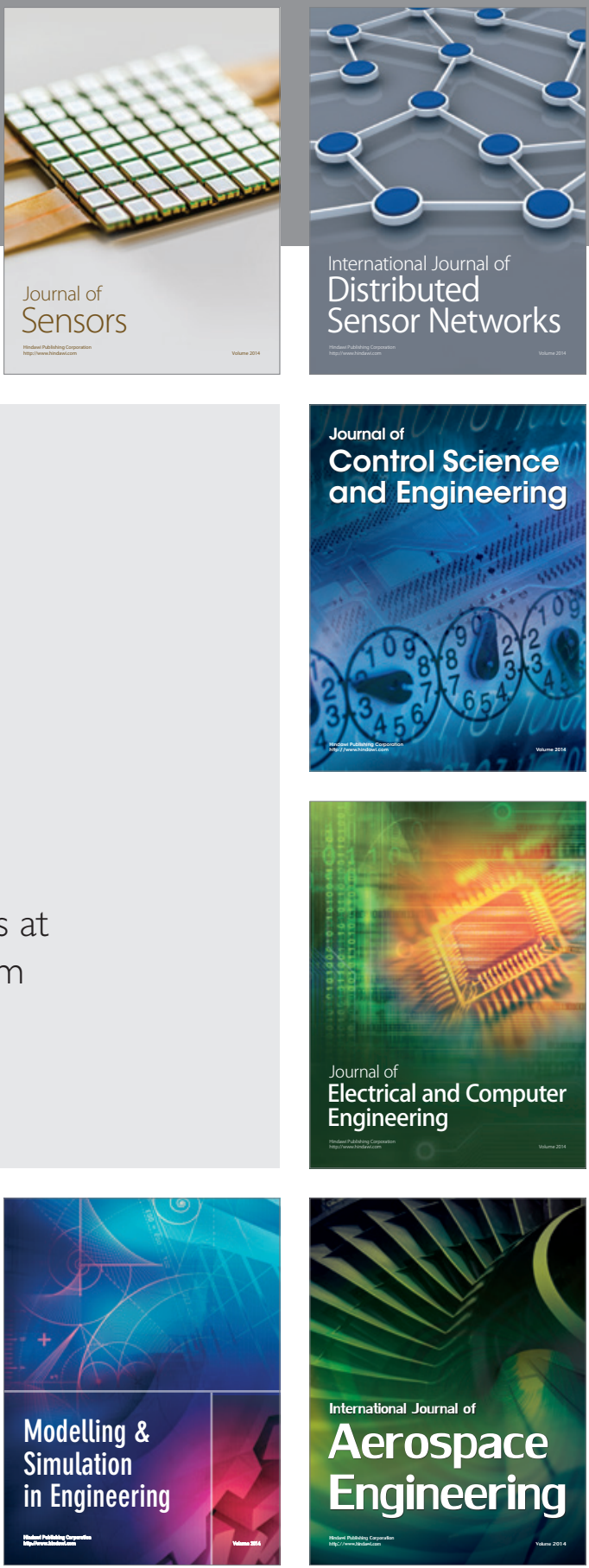

Journal of

Control Science

and Engineering
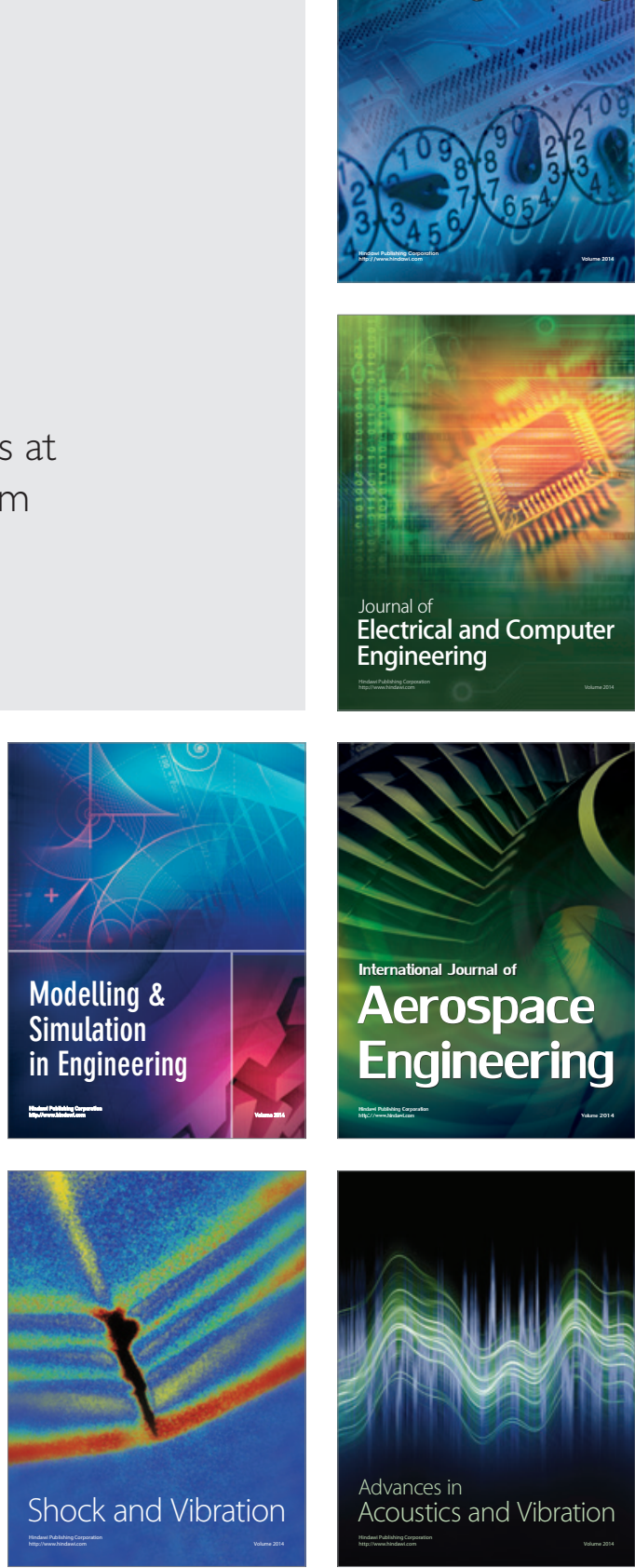